\title{
PUB16 gene expression under abiotic stress and their putative role as an ARM repeat protein in Arabidopsis thaliana self-pollination pathway
}

\author{
María Gabriela Acosta ${ }^{1,2}$, Miguel Ángel Ahumada ${ }^{2,3}$, Sergio Luis Lassaga ${ }^{2,3}$, Víctor Hugo Casco ${ }^{1,3}$ \\ ${ }^{1}$ Microscopy Laboratory Applied to Cell and Molecular Studies, Engineering School, National University of Entre Rios, Oro Verde, \\ Argentina \\ ${ }^{2}$ Biotechnology Laboratory, Genetics and Plant Breeding Department, INTA-Estación Experimental Agropecuaria Paraná, Oro Verde, \\ Argentina \\ ${ }^{3}$ Agricultural Sciences School, National University of Entre Rios, Oro Verde, Argentina \\ Email: vcasco@bioingenieira.edu.ar
}

Received 13 June 2012; revised 20 July 2012; accepted 14 August 2012

\begin{abstract}
The armadillo repeat super-family proteins (ARM repeat super-family proteins) possess tandem armadillo repeats and have been postulated to play different roles in plant development, morphogenesis, defense, cell death, and signal transduction through hormone signalling. In The Arabidopsis Information Resource (TAIR), we found 113 loci closely related to ARM repeat family proteins. This extensive group of proteins was studied in flowers tissues by western blot using antibodies directed against the most conserved region of the ARM repeat family proteins. The amino acid residues sequences from TAIR were aligned and the resulting phylogenetic tree allows us to inferring their evolutionary relationships. The main finding was the high similarity between the gene product of PUB16 (At5g01830, A. thaliana) and ARC1 (Brassica napus). In order to search a possible role for PUB16 we carried out stress bioassays using hormonal and saline approaches. Gene expression using RT-PCR showed that some of the ARM repeat super-family proteins are expressed both under salt or hormonal stress conditions. Particularly these studies allowed to detect and semi-quantify PUB16 gene expression in normal or stress growth conditions. In this approach it was revealed that, only in presence of GA, the expression of mRNA-PUB16 became evident. To morphologically verify the increasing number of germinated pollen grain in gibberellins treated flowers, we used epi-fluorescence microscopy assay. These results suggest that PUB16 may participate in GA signaling pathway favoring self-pollination.
\end{abstract}

Keywords: Self-Pollination; ARM Repeat; Gibberellins

\section{INTRODUCTION}

ARM repeat family proteins are present in animal and plants and they are known to play key roles in several cellular processes including, signal transduction, cytoskeletal regulation, nuclear import, transcriptional regulation, and ubiquitination [1]. This kind of proteins are found in the proteomes of almost all eukaryotic organisms and possesses ARM repeat domains, each one are constituted by multiple of 42 amino acid residues. The ARM domain is a highly conserved right handed super helix involved in protein-protein interactions. ARM repeat domains in plants have evolved as unique domain organizations, such as the U-box and ARM domain combination, with specialized functions. The plant-specific U-box/ARM domain proteins are the largest family of ARM repeat proteins in all the genomes surveyed and recent data have implicated these proteins as E3 ubiquitin ligases [2]. While functions have not been assigned for most of the plant ARM repeat proteins, recent studies have suggested their importance in multiple processes such as self-incompatibility (SI), hormone signaling and disease resistance [3]. U-box proteins are also involved in very important plant specific pathways [4] such as SI, Pseudo-Self-Compatibility (P-SC) [5]; and abiotic stress responses [6].

Pollination is a crucial step in the life cycle of Angiosperms, the most important cell-cell interaction in flowering plants and this is the mating system adopted by plants species where the pistil is fully developed and composed of stigma, style and ovary [7]. This process is influenced by several factors: stigmas types (i.e. dry stigma or wet stigma) and stigma receptivity (defined as ability to "capture" pollen by adhesion). The appropriate stage of stigma development is crucial for receptivity: on the mature stigma, mature pollen can adhere, hydrate and 
germinate. An efficient pollination between pollen grain and pistil is dependent on the ability of the pollen grain to adhere effectively to stigmatic surface [8].

Pollination can be classified in two categories, selfpollination (or autogamy) and cross-pollination (or allogamy). In nature there is always support for cross-pollination because this process ensures the species maintenance and contributes to increase the genetic variability in order to provide to species more ability to adapt to new environments $[9,10]$. To avoid inbreeding and promote out-crossing, many plants have adopted SI systems [11]. In SI plants, pollen will not develop on a stigma that expresses the same $\mathrm{S}$ (sterility) alleles as the pollen parent [12].

Members of the Brassicaceae have a dry stigma and one of the interesting features of this trait is the early selectivity of pollen capture following pollination $[13,14]$. Once pollen grains come into contact with stigmatic papillae, only pollen grains recognized as compatible are accepted, thus allowing plants to ignore foreign pollen. These compatible interactions appear to be specific to species within the family, but clearly can occur beyond the species level [15]. For example, success pollinations, as measured by pollen tube penetration into the stigma, have been observed in interspecific and intergeneric crosses in the Brassicaceae [16-18]. Arabidopsis belongs to the Brassicaceae family and therefore has dry stigma with many large unicellular papillae that interact directly with the pollen [19]. The sequential events from pollen adhesion to the path of pollen tube growth through the pistil to the ovule for fertilization have been carefully documented at ultrastructural level in Brassica spp. and Arabidopsis thaliana [20-25]. The best characterized pollen-pistil interaction on dry stigma is SI response in Brassica [13]. Breakdown of the pollination barrier SI in older flowers, a phenomenon known as P-SC or transient SI, has been described as an advantageous reproductive assurance strategy that allows self-pollination when opportunities for out-crossing have been exhausted $[5,26]$. The SI phenomenon seems to be controlled sporophytically by a single $\mathrm{S}$ locus with multiple alleles or variants and a set of complex dominance relationship between alleles [2729]. Its components constitute the male determinant SCR [30-34], the female determinant SLG secreted by the stigma into the cell wall, SRK located in the stigmatic plasma membrane and its ARC1target, also produced in the stigma [19]. ARC1 is a protein required in the Brassica pistil for rejection of pollen self-incompatible; it function downstream of the SRK. ARC1 promotes the ubiquitination and proteosomal degradation of compatibility factors in the pistil, which in turn leads to pollen rejection [35]. ARC1, a positive regulator of Brassica SI protein, was originally identified in a screen for proteins interacting with the active SRK kinase domain and binds to the phosphorylated kinase domain through its ARM domain [36]. The active SRK kinase domain can also cause the re-localization of ARC1 from the cytosol to the ER-associated proteasomes when it is transiently expressed in tobacco BY-2 cells [35]. A second kinase in Brassica SI signalling, the cytoplasmic Ser/Thr protein kinase, designated as M-Locus Protein Kinase (MLPK), also causes the re-localization of ARC1 to the perinuclear region and quite efficiently phosphorylates ARC1 in vitro, suggesting that MLPK may co-regulate ARC1 in conjunction with SRK [37-40].

The proposed model predicts seven ARM domains in ARC1 amino acid residue sequence C-terminal end [35]. ARM repeat super-family proteins shared a conserved three-dimensional structure: tandem ARM repeat form a right-handed super-helix of alpha-helices [1] and they mediate different cellular processes including signal transduction, cytoskeleton regulation, nuclear import, transcriptional regulation and ubiquitination [2]. There are hundreds of eukaryotic proteins with theses tandem structural units. The first member of the gene family to be characterized in detail was the mutant phenotype Drosophila segment polarity gene armadillo [41]. In mammals, their homologue $\beta$-catenin, it is known to function in several mechanisms during development, regulating gene expression and cell-cell adhesion [1].

The existence of ARM repeat family proteins in plants may possess very different functions in signal transduction and development, including morphogenesis, defense and cell death, and allow us to predict a mechanism that has been conserved throughout eukaryotic evolution. A large subset of Arabidopsis proteins similar to $\beta$-catenin (i.e. ARABIDILLO-1 and -2) contain ARM domain; they are part of the PUB family $[1,2,42]$. In this work we analyze, compare and predict evolutionary relationship between ARM repeat super-family proteins, present in the Arabidopsis genome [43]. The objective of the present work was to study the gene expression of PUB16 under abiotic stress and their possible role as an ARM repeat protein in self-pollination pathway.

\section{MATERIAL AND METHODS}

\subsection{Plant Material}

\subsubsection{Plant Growth Condition}

Arabidopsis thaliana (L.) wild-type ecotype Columbia-0 [Col-0] plants were grown on a mix of sterile soil (autoclaved before use), vermiculite-perlite and humus. Growth chamber was adjusted to $23^{\circ} \mathrm{C}$ and $70 \%$ humidity with a 16/8 h light/dark photoperiod under fluorescent illumination supplemented by incandescent light yielding an intensity of $100-150 \mathrm{mE} / \mathrm{m}^{2} \cdot \mathrm{s}$. The modified Hoagland solution used to irrigate the plants was done according [44]: $\left(\mathrm{NO}_{3}\right)_{2} \mathrm{Ca} \cdot 4 \mathrm{H}_{2} \mathrm{O} 0.55 \mathrm{mM} ; \mathrm{NO}_{3} \mathrm{~K} 0.52$ 
$\mathrm{mM} ; \mathrm{SO}_{4} \mathrm{Mg} \cdot 7 \mathrm{H}_{2} \mathrm{O} 0.22 \mathrm{mM} ; \mathrm{PO}_{4} \mathrm{H}_{2} \mathrm{~K} 0.11 \mathrm{mM} ; \mathrm{BO}_{3} \mathrm{H}_{3}$ $0.046 \mu \mathrm{M} ; \quad \mathrm{SO}_{4} \mathrm{Zn} \cdot 7 \mathrm{H}_{2} \mathrm{O} 0.00076 \mu \mathrm{M} ; \mathrm{SO}_{4} \mathrm{Cu} \cdot 5 \mathrm{H}_{2} \mathrm{O}$ $0.00031 \mu \mathrm{M} ; \mathrm{Cl}_{2} \mathrm{Mn} \cdot 4 \mathrm{H}_{2} \mathrm{O} 0.0078 \mu \mathrm{M} ; \mathrm{MoO}_{4} \mathrm{Na}_{2} \cdot 2 \mathrm{H}_{2} \mathrm{O}$ $0.00045 \mu \mathrm{M} ; \mathrm{SO}_{4} \mathrm{Fe} \cdot 7 \mathrm{H}_{2} \mathrm{O} 9 \mathrm{mM}$; $\mathrm{NaOH} 25 \mathrm{mM}$. The irrigation frequency was two times weekly with $200 \mathrm{ml}$ of modified Hoagland solution per plate $(15 \mathrm{~cm} \times 55 \mathrm{~cm})$ containing 64 pots (one plant/pot).

\subsubsection{Stress Induction}

For the ABA treatments, $(100 \mu \mathrm{M}$ and $200 \mu \mathrm{M}$ during 2 , $4,8,11$ or 24 hours) 50 open flowers randomly selected from different plants (stage 13 according to [45]), were placed on a Styrofoam disc with small holes containing the ABA solutions. All the setup was placed into a Petri disc. For both ABA concentrations, and the five times assayed, the experiment was replicated twice. The ABA treated flowers were frozen and stored in liquid $\mathrm{N}_{2}$ until use for RNA and proteins extraction. As experimental control, ABA was replaced by vehicle $\left(\mathrm{bdH}_{2} \mathrm{O}\right)$.

The GA treatment was done in flowering plants (stage 13 according to [45]) using triple spray every 2 days with $100 \mu \mathrm{M}$ and $1000 \mu \mathrm{M}$ of $\mathrm{GA}_{3}$ in controlled chamber growth conditions. The experiment was replicated twice. From each replicate 50 stressed flowers were randomly collected, frozen and stored in liquid $\mathrm{N}_{2}$ until use for RNA and proteins extraction. As experimental control, GA was replaced by vehicle $\left(\mathrm{bdH}_{2} \mathrm{O}\right)$.

Salt stresses were performed using $50 \mathrm{mM}$ and 100 $\mathrm{mM} \mathrm{NaCl}$ for 10 days from rosette of 8 leaves according to [46]. Subsequently, we return to the Hoagland solution irrigation. The experiment was replicated twice. From each replicate, 50 stressed flowers were randomly collected, frozen and stored in liquid $\mathrm{N}_{2}$ until use for RNA and proteins extraction. As experimental control, $\mathrm{NaCl}$ was replaced by Hoagland solution.

\subsection{Identification of ARM Repeats Super-Family Proteins in the Arabidopsis Genome}

\subsubsection{Sequence Analysis}

Sequences data were obtained from TAIR (The Arabidopsis Information Research: http://www.arabidopsis.org/) and BLAST (http://blast.ncbi.nlm.nih.gov/) searches were performed on NCBI (National Center for Biotechnology Investigation). Construction of multiple sequence alignments were carried out using Clustal XI 2.0 sequence analysis software [47] (http://www.clustal.org/clustal2/).

\subsubsection{Secondary Structure Prediction}

Secondary structure was predicted using programs and database available at website. Domains present were defined by SMART (Simple Modular Architecture Research Tool: http://smart.embl-heidelberg.de/) and Pfam (domains Proteins and families protein database: http://www.sanger.ac.uk/resources/databases/pfam.html) through UniProt (Universal Protein Resource: http://www.uniprot.org/) data base.

\subsubsection{Phylogenetic Analysis}

Neighbor joining trees were constructed from multiple alignments using $\mathrm{NJ}$ plot software

http://pbil.univ-lyon1.fr/software/njplot.html [48].

\subsection{Pollination Assay and Epi-Fluorescence Microscopy}

For optical and fluorescence microscopy, individual open flowers [floral stages as defined elsewhere [45,49] from fresh wild-type or stressed inflorescences were dissected; outer organs were removed using stainless steel needles under dissection microscope. Pollination tests [50] were performed on 30 pistils, fixed for $1 \mathrm{~h}$ in ethanol/acetic acid 3:1 vol/vol]. After washing with distilled water (three times), pistils were softened in $1 \mathrm{~N} \mathrm{NaOH}$ for 10 min at $65^{\circ} \mathrm{C}$ then neutralized in $50 \mathrm{mM}$ phosphate buffer saline ( $\mathrm{pH} 7.5)$. Finally samples were stained for 2 hours with decolorized aniline blue (Sigma) at $50 \mathrm{mg} / \mathrm{ml}$ in 50 $\mathrm{mM}$ phosphate buffer saline $(\mathrm{pH} 7.5)$ and mounted on slides. As control of the specific stain, non-pollinated stigmas were used. Examination and quantification by epifluorescence microscopy (Olympus BX50) of adhering and penetrating pollen grain in wild-type pistils compared to $\mathrm{GA}_{3}$ treatment was performed using UV light (excitation filter $395 \mathrm{~nm}$ and emission filter $420 \mathrm{~nm}$ ).

\subsection{RT-PCR}

Total RNA was isolated using Trizol (Invitrogen). RNA quality and concentration was measured by UV-spectrometry at 260, 230 and $280 \mathrm{~nm}$, its integrity was checked on $1.5 \%$ agarose gel and treated with DNaseI, Rnase Free (Fermentas). First-strand cDNA was synthesized from $2 \mu \mathrm{g}$ of total RNA treated with DNase in 20 $\mu l$ of reaction volume, using M-MuLV reverse transcripttase (Fermentas). One-tenth of the first-strand cDNA was used as a template in a $25 \mu \mathrm{l} \mathrm{PCR}$ of 25 cycles $\left(96^{\circ} \mathrm{C}\right.$ for $2 \mathrm{~min}, 94^{\circ} \mathrm{C}$ for $1 \mathrm{~min}, 66.8^{\circ} \mathrm{C}$ for $1 \mathrm{~min}$ and $72^{\circ} \mathrm{C}$ for 1 min) using gene-specific primers. PCR products were analyzed by electrophoresis in $2 \%$ agarose gels and visualized with UV light before cDNA synthesis (First Strand cDNA Synthesis, Fermentas). $\beta$-tubulin (At5g62700) was used as internal control. Primers F1: GAGAATGCTGA TGAGTGCATGG/R1: CAGGGAACCTCAGACAGCA AGT (for Tubulin) and F2: AATCGCCGGGATCAAG CACC/R2: GTGGCGGCGGAAATCTGGAG (for At5g 01830). DNA extraction: $50 \mathrm{mg}$ of tissue was freeze in liquid nitrogen and extensively pulverized using a micropestle. Genomic DNA extraction was carried out using 
the NucleoSpin ${ }^{\circledR}$ Plant II Genomic DNA kit according to manufacturer's specifications. To check the genomic DNA integrity a $1.5 \%$ agarose gel was prepared [51].

\subsection{Western Blot}

Total protein extracts from Arabidopsis thaliana were obtained by $\mathrm{N}_{2}$-freezing and grinding $50 \mathrm{mg}$ of floral tissue according to [52]. Total protein concentration was determined in the supernatant by the Bradford's assay [53], using BSA as standard. Samples were loaded on two standards SDS-PAGE 10\% [54], transferred to PVDF membrane and to perform the western blot assay [51]. The primary antibody choice was based on previous evaluation (WebLogo 3.0 software: http://weblogo.three plusone.com/) of the amino acids residues conservation degree in A. thaliana ARM repeats (not shown). Since it exhibits a low-level of amino acid residues conservation, we used an antibody that covers a wide area of ARM repeats. Thus we choose the polyclonal antibody antiARMC8 (H-300: sc-98534, Santa Cruz Biotechnology, Inc.) since it recognizes 7 ARM repeats of the 14 present in the protein. ARMC8 is a rabbit polyclonal antibody directed against amino acids residues 311 - 610 mapping within an internal region of ARMC8 of human origin.

\subsection{Statistical Analysis}

Statistical analysis was performed using test pollination results carried out in stressed floral tissue $(+\mathrm{GA})$ and control floral tissue (-GA). The data were analyzed by a one-way analysis of variance using the SAS software (Statistical Analysis Systems, SAS. Institute, Inc., 1999). Results of analysis of variance (ANOVA) and Tukey mean differences test $(\alpha=0.05)$ was performed for number of pollen grains per stigma in plants with gibberellin $(+\mathrm{GA})$ and control plants $(-\mathrm{GA})$.

\section{RESULTS AND DISCUSSION}

Earlier studies of the Arabidopsis proteome have found both large number of predict ARM repeat super-family proteins as well as a variety of domain organizations associated with ARM repeats [2,42,55-57]. The largest class of ARM repeats family proteins belong to the PUB proteins and some of them share very similar 3D structures (Figure 1; [2]). As was previously postulated by Mudgil et al. 2004 [42], the fewer number of ARM repeats observed in AtPUBs and the 3D structural homology exhibited by PUB16, PUB17 and ARC1 in our studies, may be related with the acquisition of new functions. Most of the ARM repeats family proteins function as E3 ubiquitin-ligases [56] in the regulation of cell death [58] and defense [59] mediating proteasome-dependent degradation. This ubiquitin-proteasome pathway is used by
GA signaling pathway, like auxin and jasmonate ones, to control gene expression through protein degradation [60, [61]. Since GA behaves as a "florigen" for long-day plants [62] and being a class of hormone involved in the regulation of flower development in Arabidopsis [63], we have analyzed how gene expression in flowering time is affected both under normal growth conditions and GA treatment. As antagonist phytohormone to GA, we decided to use ABA, because it is highly linked to the expression of E3 ubiquitin ligases in other models $[64,65]$.

To characterize these ARM repeat super-family proteins, we performed western blot technique using ARMC8 as primary antibody. The immunoblot assay allowed us to identify most of $A$. thaliana ARM repeat proteins, grouped in three very well defined clusters in all stressed plants (30 to $37 \mathrm{kDa} ; 55$ to $60 \mathrm{kDa}$ and 75 to $80 \mathrm{kDa}$ ). Contrasting, only two bands were observed both under normal growth conditions (55 to $60 \mathrm{kDa}$ and 75 to 80 $\mathrm{kDa}$ ) (not shown).

In order to determine whether it is a unique protein or a cluster, we compare the molecular weights of 113 loci for putative polypeptides available in TAIR website. Accordingly, the candidates were grouped into 3 major molecular weight clusters: group A, between 75 to 80 $\mathrm{kDa}$; group $\mathrm{B}$, between 55 to $60 \mathrm{kDa}$; and group $\mathrm{C}$, between 30 to $37 \mathrm{kDa}$. Group A corresponds to five putative ARM repeat proteins: AT5G01830, AT1G60190, AT5G67340, AT4G31520 and AT4G36550; group B corresponds to the six putative ARM repeat proteins: AT1G23940, AT4G31890, AT5G50900, AT5G22820, AT2G45720 and AT3G1518; and group C corresponds to eight putative ARM repeat proteins: AT3G43260, AT4G15830, AT5G11550, AT3G58180, AT1G08315, AT5G14510, AT3G01450 and AT1G15165. From this study we can remark two important facts: first of all the expression of ARM repeat proteins from groups A and B were increased in stressed conditions and second, the appearance of a new band corresponding to the group $\mathrm{C}$ in stressed experiments. From these results we can conclude that the group $\mathrm{C}$ corresponds to ARM repeat proteins expressed specifically in floral tissue under the stress conditions evaluated.

Following was performed a bioinformatics search in order to decide which of the three putative ARM repeat protein groups must be focused for gene expression studies. The alignment of 113 loci for putative polypeptides available in TAIR website was performed by comparing their amino acid residue sequence with the ARC1 ones. This comparison yielded 57 final candidates, 19 of which have U-box sequences in addition to the ARM sequences. Within this group, there are two protein sequences closely related to ARC1: AT1G29340 (PUB17) and AT5g01830 (PUB16), been the very well-known PUB17, the most closely related to ARC1, followed by 

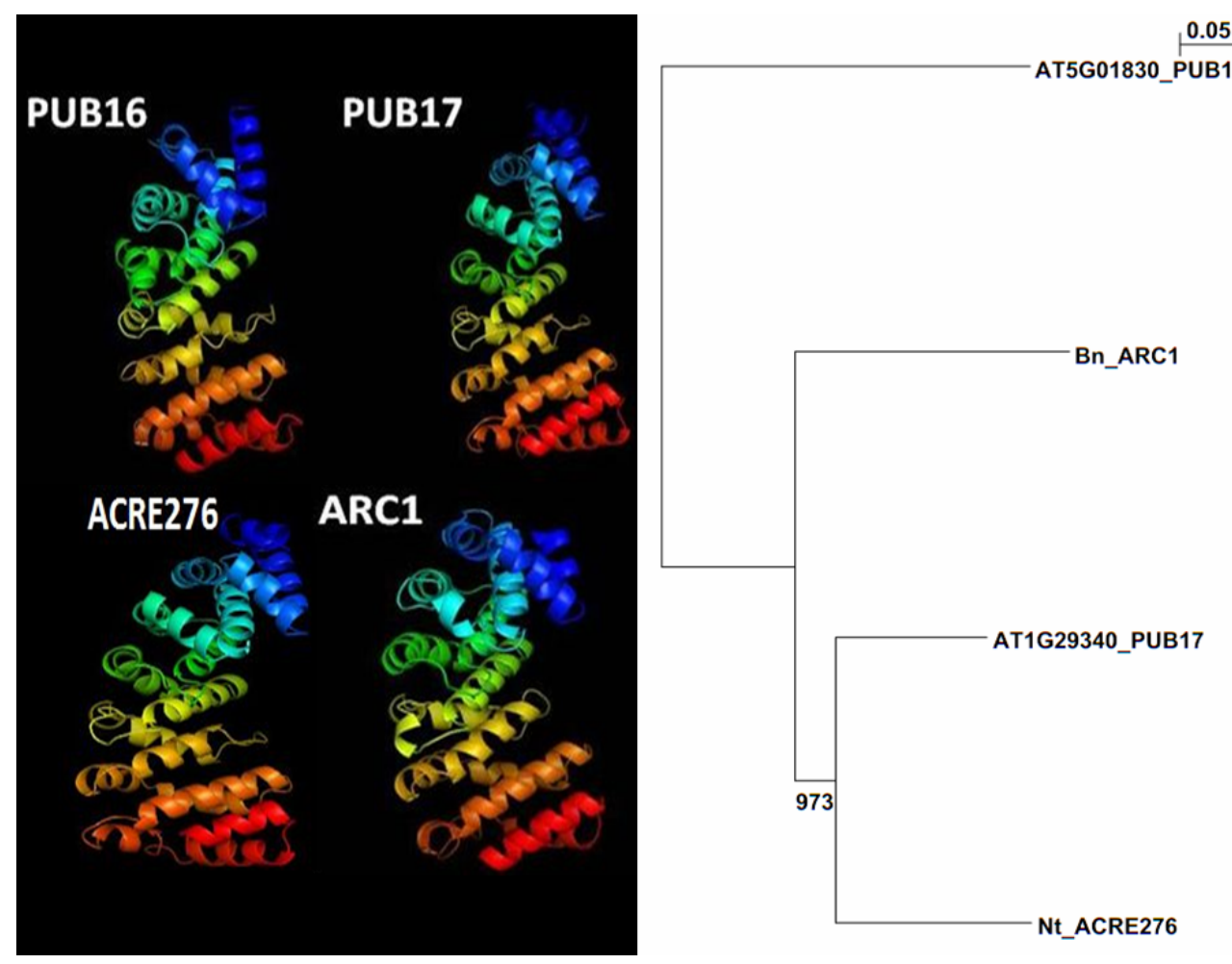

Figure 1. 3D structure and evolutionary relationship predictions of ARM repeat proteins. At the left: PyMol molecular visualization tool where can be seen similarities in the spatial C-terminal ARM repeats folding pattern of: ACRE276, ARC1, PUB16 and PUB17 (Acosta 2010). At the right: is shown the phylogenetic tree resulting from the evolutionary relationship between them. We used the software available online iTol (Interactive tree of life [http://itol.embl.de/upload.cgi]) [77]. The Neighbour Joining algorithm has been used to allow tree construction and indicated in each node the bootstrap values. Evolutionary distance is shown in the upper right.

PUB16. PUB17 function as putative E3 ubiquitin ligase contains four ARM repeats and a U-box domain and it was widely studied. Its functional tobacco homolog ACRE276 is required for cell death and defense in Solanaceae [59]. The BLASTp alignment ARC1/PUB17 produced $58 \%$ identity and $74 \%$ similarity $(\mathrm{E}-\mathrm{value}=0)$ and ARC1/PUB16 display 34\% identity and 51\% similarity $\left(E-v a l u e=1 e^{-75}\right)$. Similarly, the scores obtained from ClustalX were: PUB16/ARC1: 31; ACRE276/ PUB16: 35; PUB17/PUB16: 36; ACRE276/ARC1: 53; PUB17/ARC1: 60 and ACRE276/PUB17: 68 (Figure 2). PUB16 contains three ARM repeats and one U-box domain, so we can infer that it could functions as E3 ubiquitin-ligase. However, similarity at the amino acid residue does not allowed us to deduce similar functions in pollen-stigma recognition mechanism in B. napus and $A$. thaliana.

PUB17 is an E3 ubiquitin ligase and has been postulated that it may form a signaling complex with a SRK1-like kinase analogous to the SRK/ARC1/thioredoxin complex in B. napus during rejection of self-incompatible pollen in Brassica $[36,66]$.

Because PUB17 has already been fully characterized and their possible function has been inferred [59], we decided to study PUB16, which according to the alignment and phylogenetic analysis is the other ARC1-like $A$. thaliana ARM repeat protein.

PUB16 could belong to the ARM repeat proteins from the group A detected on western blot and their hypothetical characterization was performed using the UniProt database (http://www.uniprot.org/) which freely provides accessible resource of protein sequence and functional information. The five sequences belonging to the group A (AT4G31520, AT5G01830, AT1G60190, AT5G67340 and AT4G36550) have been evidenced only at transcriptional level. According to this result, we cannot establish which of the five possible peptides correspond to the expression band observed in our western blot results and should be clarified in future experiments.

Therefore, as a first step, we decided to start the studies evaluating the PUB16 transcription levels in normal and different stress conditions at the same flowering stage. Expression studies using RT-PCR technique for subsequent semi-quantification of PUB16 revealed that in presence of $\mathrm{GA}_{3} 1000 \mu \mathrm{M}$, there is a significant gene expression of this molecule; while there is no expression 


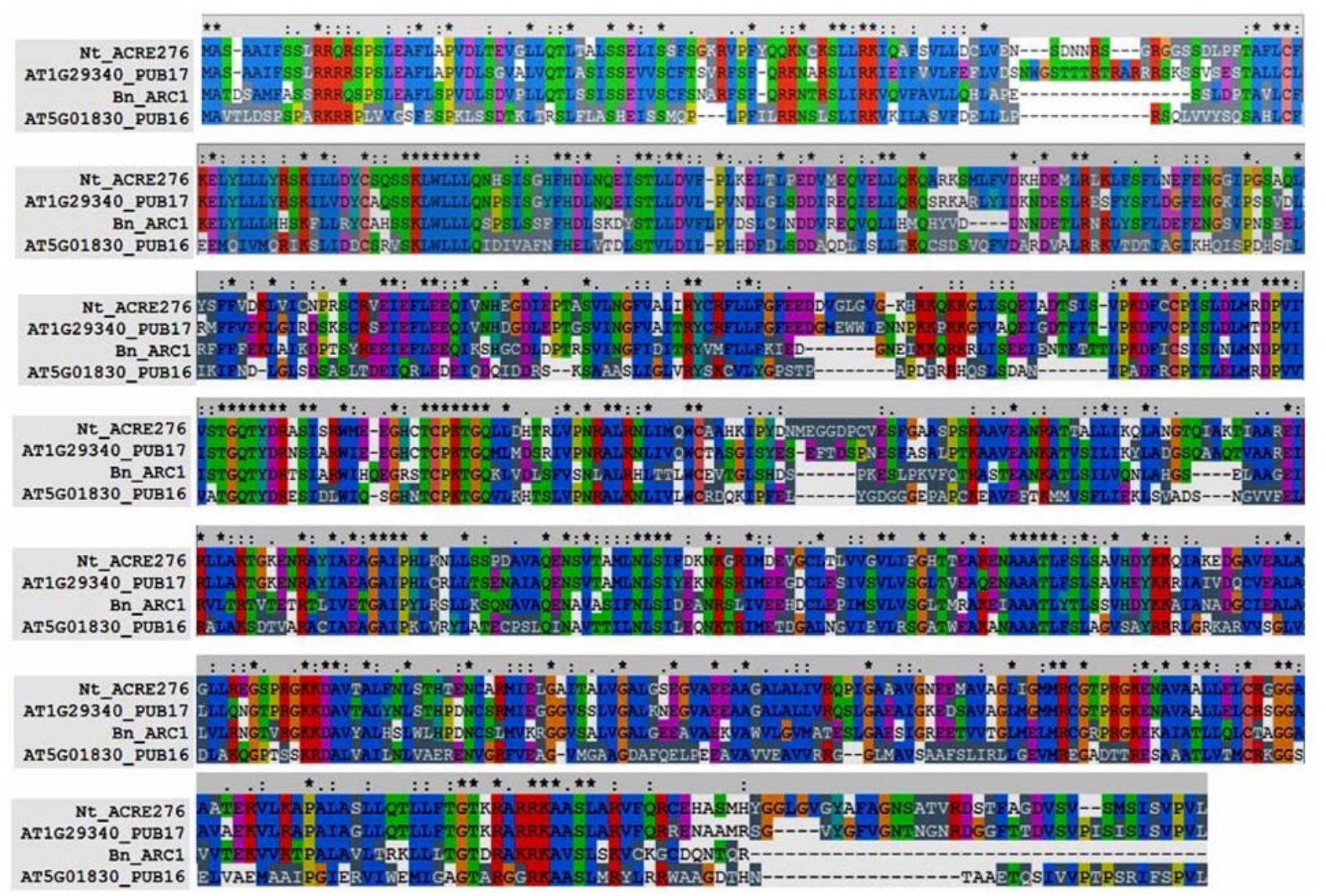

Figure 2. Multiple alignments between ACRE276, ARC1, PUB17 and PUB16. The sequences aligned were: Nt_ACRE276, Bn ARC1, At1g29340_PUB17 and At5g01830 PUB16. The default colour scheme is according to ClustalX. In grays box is shown low scoring segments. An "*” (asterisk) indicates positions which have a single, fully conserved residue. A ":" (colon) indicates conservation between groups of strongly similar properties - scoring > 0.5 in the Gonnet PAM 250 matrix. A “.” (period) indicates conservation between groups of weakly similar properties - scoring $\leq 0.5$ in the Gonnet PAM 250 matrix.

in normal growth conditions (-GA) neither in ABA (Figure 3) nor $\mathrm{NaCl}$ treatments (not shown).

Recent studies by Griffiths et al. 2007 [67] have demonstrated that flowering genes only are expressed if the repression system exercised by the nuclear proteins DELLA is disassembled by GA signalling pathway. According to these, our PUB16 polypeptide could be involved in a regulation pathway of proteosome degradation mediated by E3 ubiquitin ligases, specifically, downregulating genes involved in inhibition of SC.

Furthermore, the plant phenotypes were also affected by the addition of exogenous GA. Stressed plants $(+\mathrm{GA})$ showed lower altitudes and flowered earlier compared to those grown in normal conditions $(-\mathrm{GA})$. This change in the plant height corresponds to the classical effect of GA that regulates growth and influences various developmental processes, including stem elongation. These results are consistent with previously published studies which demonstrate that in Arabidopsis, physiological and genetic experiments have implicated GA specifically in the autonomous pathway of flowering. Exogenous ap- plication of GA accelerates flowering in wild type Arabidopsis [68].

Finally, the morphological analysis was done to confirm if there is a significant increase of self-pollination in GA sprayed flowers. This approach allowed us to corroborate that $A$. thaliana $\mathrm{L}$. is self-compatible with pollen grains produced by the same plant. When plants were sprayed with GA, it was showed greater number of pollen grains germinated and adhered on stigmatic surface $(+\mathrm{GA})$ than control plants (-GA) (Figure 4). It is very well known that the phytohormone GA regulates and participates in development and fertility of $A$. thaliana $\mathrm{L}$. flowers. However, it is not clear how GA regulates the late-stage development of floral organs after the establishment of their identities within floral meristems [63].

Our results does show that mRNA-PUB16 was specifically detected under hormonal stress by exogenous GA (+GA) and they are absent without GA (-GA). Also, by western blot, it was observed an increased expression at the protein level in the five putative polypeptides, classified in group A, among which could be expressed 


\begin{tabular}{llclllllll}
\multicolumn{9}{c}{ ABA } & \\
\hline 2 & 4 & 8 & 11 & 24 & $+G A_{3}$ & $-G A_{3}$ & gDNA & $(-)$ \\
\hline
\end{tabular}

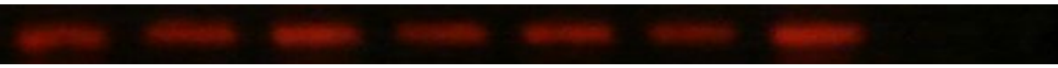

Figure 3. RT-PCR: agarose gels stained with ethidium bromide Amplification of two products: $241 \mathrm{bp}$ (PUB16, at the top) and $151 \mathrm{bp}$ (internal control $\beta$-tubulin, at the bottom). Treatment with $\mathrm{ABA} 100 \mu \mathrm{M}$ was performed for 2, 4, 8, 11 and 24 hours but only internal control it was expressed, as well as in normal conditions (-GA). Only with GA3 $1000 \mu \mathrm{M}(+\mathrm{GA})$ it was observed PUB16 gene expression. Positive control: gDNA as PCR template; negative control: PCR without cDNA template (-). Also, it was performed RT-PCR controls: RNA treated with and without DNase subjected to retro-transcription (not shown).
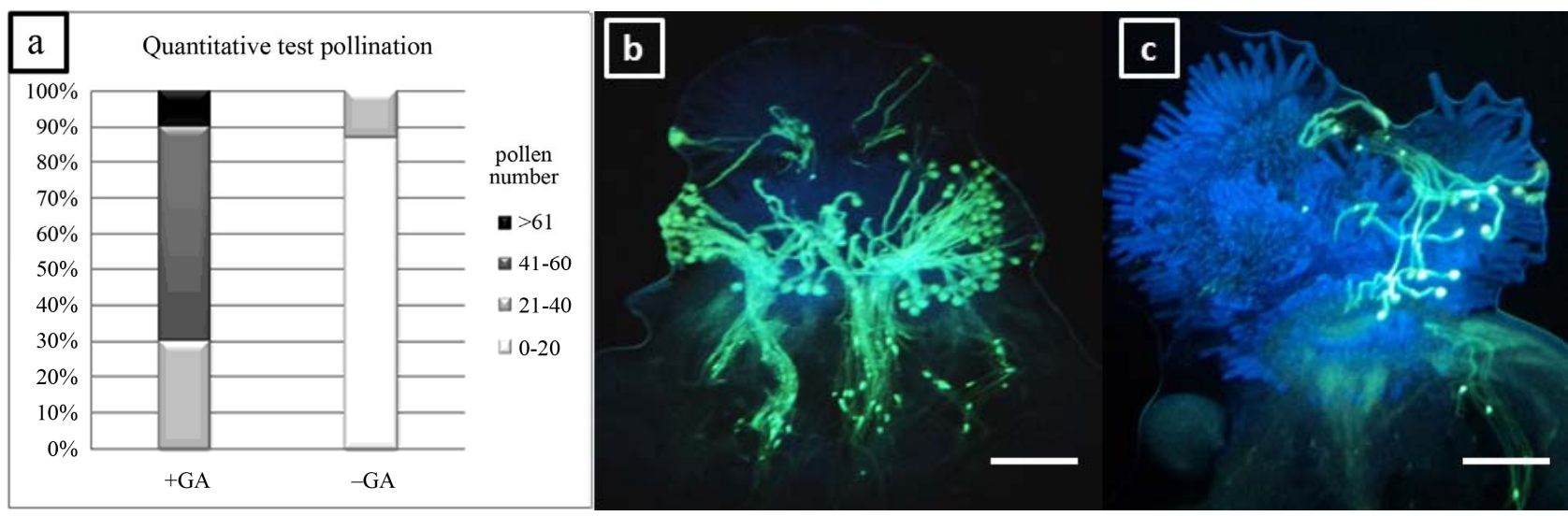

Figure 4. Pollination in pistils with and without GA. (a) Analysis of variance using a conventional statistical test (Tukey mean differences test) allow to determine that the application of $\mathrm{GA}_{3}(+\mathrm{GA})$ in the plants increased significantly $(p<0.001)$ the number of pollen grains on pistils compared to plants sprayed without hormone (-GA). The quantitative analysis was carried out using self-pollinated flowers (state 13, Bowman 1994), they were classified into four classes according to the number of pollen grains (adhering and tubes penetrating the stigma): 0 - 20, $21-40,41-60$ and $>60$ pollen grains. A notable increase in germinated pollen grains number on the stigma under hormonal stress conditions can be clearly seen in images corresponding to aniline blue stained pollen grains on the flower; (b) + GA and (c) - GA. Bar $=50 \mu \mathrm{m}$ (ImageJ: http://rsbweb.nih.gov/ij/).

our PUB16 candidate.

Performing bioinformatics in-silico studies, we were able to demonstrate that the secondary and tertiary structures of PUB16 putative protein, PUB17 and ARC1 exhibit a highly similar pattern, suggesting similar functions for both molecules. Like PUB17 and ACRE276 (functional homolog's see Figure 1: ARM repeat protein implicating the ubiquitin proteasome system in defenses against pathogens in Nicotiana tabacum) could be E3 ligase activity required for plant cell death. Like ARC1, in SI systems, PUB16 may be a signaling pathway player in SC systems, even though in this particular interaction mechanism, the expression level would be regulated by GA.

The present work suggests that GA promotes PUB16 gene expression; however, since their target substrates have not yet been identified, we cannot propose how it works. Studies of GA signal transduction, using genetic approaches, have led to the identification of positive and negative signaling components [69]. Among these, the most extensively characterized are the DELLA proteins. The molecular mechanism by which DELLA proteins suppress GA responses is not yet clear. The A. thaliana genome contains five DELLA genes (RGA, GAI, RGL1, RGL2, and RGL3). A major GA-signaling cascade has been recently discovered [70]: GA binding to their soluble GA receptor GAIN SENSITIVE DWARF1 (GID1), triggering its interaction with DELLA proteins [67]. This interaction stimulates binding of the DELLA proteins to an E3 ubiquitin ligase via specific F-box proteins, leading to polyubiquitination and degradation of the DELLA protein by the $26 \mathrm{~S}$ proteosome. While this relatively simple GA-signaling cascade involves three major players: a receptor, a DELLA protein, and a F-box protein, other studies have identified additional factors that affect GA responses [71]. It will be interesting to clarify whether E3 ubiquitin ligases genes are simply the downstream targets of DELLA proteins or whether they may 
also interact with DELLA proteins as region-specific cofactors. Interactions studies have been used to identify candidates [72] and in vitro ubiquitination assays can be used to confirm the ability of E3 ligases to ubiquitinate these potential substrates [73-75]. However, at present, have not been identified yet the ARC1 potential targets. Additionally, with the identification of the biological roles of putative PUB proteins, the understanding about how these E3 ligases are activated is an equally important step in the elucidation of their physiological functions.

\section{CONCLUTIONS}

ARM repeat super-family proteins, like related proteins possessing this domain, may be involved in protein-protein interactions. The ARM repeat super-family proteins analysis in this plant model, will allow a better understanding of the pollination cell biology and its possible participation in their signaling pathways. Since there is very little knowledge about GA signaling pathway, even though they are proposed to be related to plants fertility, it is very challenging to study which genes are expressed under both stress or normal growth conditions, and also it is important to temporal and functionally characterize their behavior.

In this work, sequence comparison revealed significant structural homology between ARC1 and PUB16. This close relationship allows us to infer that similar transduction pathways might exist in two Brassicaceae species differently involved in pollen hydration regulation and their signaling mechanism of self and non-self pollen recognition. Also, the results obtained here show the ARM repeat super-family proteins clustering of $A$. thaliana which is composed of three groups according to molecular weights. According to our gene expression studies, it appears that exogenous addition of GA cause PUB16 gene expression, but this not happen in normal condition growth or in ABA presence. Also, these results are consistent with previous reports that postulate that, plants ARM repeat super-family proteins expression is subjected to both salt [50] or hormonal stresses [76]. Furthermore, these outcomes suggest that $A$. thaliana could use some GA-signaling pathway which favors selfpollination, fruit set and great seed production under hormonal stress. Further analysis of ARM repeat superfamily proteins will improve understanding of their biology role related to its possible involvement in different signaling pathways.

\section{REFERENCES}

[1] Coates, J.C. (2007) Plant cell monographs: Plant growth signaling. Springer, Berlin, 299-314.

[2] Samuel, M., Salt, J., Shiu, S. and Goring, D. (2006) Mul- tifunctional arm repeat domains in plants. International Review of Cytology, 253, 1-26. doi:10.1016/S0074-7696(06)53001-3

[3] Coates, J.C., Laplaze, L. and Haseloff, J. (2006) Armadillo-related proteins promote lateral root development in Arabidopsis. Proceedings of the National Academy of Sciences USA, 103, 1621-1626. doi: $10.1073 /$ pnas. 0507575103

[4] González-Lamothe, R., Tsitsigiannis, D.I., Ludwig, A.A., Panicot, M., Shirasu, K. and Jones, J.D.G. (2006) The U-box protein CMPG1 is required for efficient activation of defense mechanisms triggered by multiple resistance genes in tobacco and tomato. The Plant Cell, 18, 10671083. doi: $10.1105 /$ tpc. 106.040998

[5] Liu, P., Sherman-Broyles, S. and Nasrallah, M.E. (2007) A cryptic modifier causing transient self-incompatibility in Arabidopsis thaliana. Current Biology, 17, 734-740. doi:10.1016/j.cub.2007.03.022

[6] Yan, J., Wang, J., Li, Q., Hwang, J.R., Patterson, C. and Zhang, H. (2003) AtCHIP, a U-box-containing E3 ubiquitin ligase, plays a critical role in temperature stress tolerance in Arabidopsis. Plant Physiology, 132, 861-869. doi: $10.1104 / p p .103 .020800$

[7] Dong, J., Kim, S.T. and Lord, E.M. (2005) Plantacyanin plays a role in reproduction in Arabidopsis. Plant Physiology, 138,778-789. doi:10.1104/pp.105.063388

[8] Wheeler, M.J., Franklin-Tong, V.E. and Franklin, F.C.H. (2001) The molecular and genetic basis of pollen-pistil interactions. New Phytologist, 151, 565-584. doi:10.1046/j.0028-646x.2001.00229.x

[9] Nasrallah, M.E., Liu, P., Sherman-Broyles, S., Boggs, N.A. and Nasrallah, J.B. (2004) Natural variation in expression of self-incompatibility in Arabidopsis thaliana: Implications for the evolution of selfing. Proceedings of the National Academy of Sciences USA, 101, 1607016074. doi:10.1073/pnas.0406970101

[10] Sanchez, A.M., Bosch, M., Bots, M., Nieuwland, J., Feron, R. and Mariani, C. (2004) Pistil factors controlling pollination. The Plant Cell, 16, S98-S106. doi: $10.1105 / \mathrm{tpc} .017806$

[11] Huang, J., Zhao, L., Yang, Q. and Xue, Y. (2006) AhSSK1, a novel SKP1-like protein that interacts with the S-locus F-box protein SLF. The Plant Journal, 46, 780-793. doi:10.1111/j.1365-313X.2006.02735.x

[12] Kusaba, M., Dwyer, K., Hendershot, J., Vrebalov, J., Nasrallah, J.B. and Nasrallah, M.E. (2001) Self-incompatibility in the genus Arabidopsis: Characterization of the $\mathrm{S}$ locus in the outcrossing $A$. lyrata and its autogamous relative $A$. thaliana. The Plant Cell, 13, 627-643.

[13] Heslop-Harrison, Y. and Shivanna, K.R. (1977) The receptive surface of the angiosperm stigma. Annals of Botany, 41, 1233-1258.

[14] Dickinson, H. (1995) Dry stigmas, water and self-incompatibility in Brassica. Sexual Plant Reproduction, 8, 1-10. doi:10.1007/BF00228756

[15] Hulskamp, M., Kopczak, S.D., Horejsi, T.F., Kihl, B.K. and Pruitt, R.E. (1995) Identification of genes required for pollen-stigma recognition in Arabidopsis thaliana. 
The Plant Journal, 8, 703-714. doi:10.1046/j.1365-313X.1995.08050703.x

[16] Sampson, D.R. (1962) Intergeneric pollen-stigma incompatibility in Cruciferae. Canadian Journal of Genetics and Cytology, 4, 38-49.

[17] Hiscock, S.J. and Dickinson, H.G. (1993) Unilateral incompatibility within the Brassicaceae: Further evidence for the involvement of the self incompatibility (S)-locus. Theoretical and Applied Genetics, 86, 744-753. doi:10.1007/BF00222665

[18] Lelivelt, C.L.C. (1993) Studies of pollen grain germination, pollen-tube growth, micropylar penetration and seed set in intraspecific and intergeneric crosses within three Cruciferae species. Euphytica, 67, 185-197. doi:10.1007/BF00040620

[19] Nasrallah, J.B. (2000) Cell-cell signaling in the self-incompatibility response. Current Opinion of Plant Biology, 3, 368-373. doi:10.1016/S1369-5266(00)00098-4

[20] Hill, J.P. and Lord, E.M. (1987) Dynamics of pollen tube growth in the wild radish, Raphanus raphanistrum (Brassicaceae) 2.Morphology, cytochemistry, and ultrastructure of transmitting tissues, and path of pollen tube growth. American Journal of Botany, 74, 988-997. doi: $10.2307 / 2443938$

[21] Elleman, C.J. and Dickinson, H.G. (1990) The role of the exine coating in pollen-stigma interactions in Brassica oleracea L. New Phytologist, 114, 511-518. doi:10.1111/j.1469-8137.1990.tb00419.x

[22] Elleman, C.J., Franklin-Tong, V. and Dickinson, H.G. (1992) Pollination in species with dry stigmas: The nature of the early stigmatic response and the pathway taken by pollen tubes. New Phytologist, 121, 413-424. doi:10.1111/j.1469-8137.1992.tb02941.x

[23] Kandasamy, M.K., Nasrallah, J.B. and Nasrallah, M.E. (1994) Pollen-pistil Interactions and developmental regulation of pollen tube growth in Arabidopsis. Development, 120, 3405-3418.

[24] Hulskamp, M., Schneitz, K. and Pruitt, R.E. (1995b) Genetic evidence for along-range activity that directs pollen tube guidance in Arabidopsis. The Plant Cell, 7, 57-64.

[25] Lennon, K.A., Roy, S., Hepler, P.K. and Lord, E.M. (1998) The structure of the transmitting tissue of Arabidopsis thaliana (L.) and the path of pollen tube growth. Sexual Plant Reproduction, 11, 49-59. doi: $10.1007 / \mathrm{s} 004970050120$

[26] Tsuchimatsu, T., Suwabe, K., Shimizu-Inatsugi, R., Isokawa, S., Pavlidis, P., Stadler, T., Suzuki, G., Takayama, S., Watanabe, M. and Shimizu, K. (2010) Evolution of self-compatibility in Arabidopsis by a mutation in the male specificity gene. Nature, 464, 1342-1346. doi:10.1038/nature08927

[27] Bateman, A.J. (1955) Self-incompatibility systems in angiosperms. III. Cruciferae. Heredity, 9, 52-68. doi:10.1038/hdy.1955.2

[28] Thompson, K.F. and Taylor, J.P. (1966) Non-linear dominance relationships between S-alleles. Heredity, 21, 345362. doi:10.1038/hdy.1966.36

[29] Tarutani, Y., Shiba, H., Iwano, M., Kakizaki, T., Suzuki,
G., Watanabe, M., Isogai, A. and Takayama, S. (2010) Trans-acting small RNA determines dominance relationships in Brassica self-incompatibility. Nature, 466, 983986. doi:10.1038/nature09308

[30] Suzuki, G., Kai, N., Hirose, T., Fukui, K., Nishio, T., Takayama, S., Isogai, A., Watanabe, M. and Hinata, K. (1999) Genomic organization of the S locus: Identification and characterization of genes in SLG/SRK region of S9 haplotype of Brassica campestris (syn. rapa). Genetics, 153, 391-400.

[31] Schopfer, C.R., Nasrallah, M.E. and Nasrallah, J.B. (1999) The male determinant of self-incompatibility in Brassica. Science, 286, 1697-1700. doi:10.1126/science.286.5445.1697

[32] Takayama, S., Shiba, H., Iwano, M., Shimosato, H., Che, F.S., Kai, N., Watanabe, M., Suzuki, G., Hinata, K. and Isogai, A. (2000) The pollen determinant of self-incompatibility in Brassica campestris. Proceedings of the $\mathrm{Na}$ tional Academy of Sciences USA, 97, 1920-1925.

[33] Takayama, S., Shimosato, H., Shiba, H., Funato, M., Che, F.S., Watanabe, M., Iwano, M. and Isogai, A. (2001) Direct ligand-receptor complex interaction controls Brassica self-incompatibility. Nature, 413, 534-538. doi: $10.1038 / 35097104$

[34] Shiba, H., Takayama, S., Iwano, M., Shimosato, H., Funato, M., Nakagawa, T., Che, F., Suzuki, G., Watanabe, M., Hinata, K. and Isogai, A. (2001) A pollen coat protein, SP11/SCR, determines the pollen S-specificity in the self-incompatibility of Brassica species. Plant Physiology, 125, 2095-2103. doi:10.1104/pp.125.4.2095

[35] Stone, S.L., Anderson, E.M., Mullen, R.T. and Goring, D.R. (2003) ARC1 is an E3 ubiquitin ligase and promotes the ubiquitination of proteins during the rejection of selfincompatible Brassica pollen. The Plant Cell, 15, 885898. doi: $10.1105 /$ tpc. 009845

[36] Gu, T.S., Mazzurco, M., Sulaman, W., Matias, D.D. and Goring, D.R. (1998) Binding of an arm repeat protein to the kinase domain of the S-locus receptor kinase. Proceedings of the National Academy of Sciences USA, 95, 382-387.

[37] Samuel, M.A., Mudgil, Y., Salt, J.N., Delmas, F., Ramachandran, S., Chilelli, A. and Goring, D.R. (2008) Interactions between the S-domain receptor kinases and AtPUB-ARM E3 ubiquitin ligase ssuggest a conserved signaling pathway in Arabidopsis. Plant Physiology, 147, 2084-2095. doi:10.1104/pp.108.123380

[38] Murase, K., Shiba, H., Iwano, M., Che, F.S., Watanabe, M., Isogai, A. and Takayama, S. (2004) A membraneanchored protein kinase involved in Brassica self-incompatibility signaling. Science, 303, 1516-1519. doi:10.1126/science.1093586

[39] Kakita, M., Murase, K., Iwano, M., Matsumoto, T., Watanabe, M., Shiba, H., Isogai, A. and Takayama, S. (2007) Two distinct forms of M-locus protein kinase localize to the plasma membrane and interact directly with S-locus receptor kinase to transducer self-incompatibility signaling in Brassica rapa. The Plant Cell, 19, 3961-3973. doi:10.1105/tpc.106.049999

[40] Kakita, M., Shimosato, H., Murase, K., Isogai, A. and 
Takayama, S. (2007) Direct interaction between the Slocus receptor kinase and $\mathrm{M}$ locus protein kinase involved in Brassica self-incompatibility signaling. Plant Biotechnology, 24, 185-190.

doi:10.5511/plantbiotechnology.24.185

[41] Riggleman, B., Wieschaus, E. and Schedl, P. (1989) Molecular analysis of the armadillo locus: Uniformly distributed transcripts and a protein with novel internal repeats are associated with a Drosophila segment polarity gene. Genes Development, 3, 96-113. doi:10.1101/gad.3.1.96

[42] Mudgil, Y., Shiu, S.H., Stone, S.L., Salt, J.N. and Goring, D.R. (2004) A large complement of the predicted Arabidopsis ARM repeat proteins are members of the U-box E3 ubiquitin ligase family. Plant Physiology, 134, 59-66. doi:10.1104/pp.103.029553

[43] Acosta, M.G., Langhi, D., Lassaga, S.L. and Casco, V.H. (2010a) Bioinformatics and morphological studies of pollination mechanism as a process of cell-cell adhesion in Arabidopsis thaliana. Agricultural Science Magazine, 14, 3-15.

[44] Epstein, E. (1972) Mineral nutrition of plants: Principles and perspectives. J. Wiley and Sons, Inc., New York, 6882.

[45] Bowman, J. (1994) Arabidopsis: An atlas of morphology and development. Springer-Verlag, New York, 258-259.

[46] Banzai, T., Hershkovits, G., Katcoff, D.J., Hanagata, N., Dubinsky, Z. and Karube, I. (2002) Identification and characterization of mRNA transcripts differentially expressed in response to high salinity by means of differential display in the mangrove, Bruguiera gymnorrhiza. Plant Science, 162, 499-505. doi:10.1016/S0168-9452(01)00601-X

[47] Thompson, J.D., Higgins, D.G. and Gibson, T.J. (1994) CLUSTAL W: Improving the sensitivity of progressive multiple sequence alignment through sequence weighting, position-specific gap penalties and weight matrix choice. Nucleic Acids Research, 22, 4673-4680. doi:10.1093/nar/22.22.4673

[48] Perriere, G. and Gouy, M. (1996) www-query: An on-line retrieval system for biological sequence banks. Biochimie, 78, 364-369. doi:10.1016/0300-9084(96)84768-7

[49] Smyth, D.R., Bowman, J.L. and Meyerowitz, E.M. (1990) Early flower development in Arabidopsis. The Plant Cell, 2, 755-767.

[50] Eschrich, W. and Currier, H.B. (1964) Identification of callose by it diachrome and fluorchrome reactions. Stain Technology, 39, 308-309.

[51] Sambrook, D.W. and Russell, J. (2001) Molecular cloning: A laboratory manual. Cold Spring Harbor Laboratory Press, New York, 102-114.

[52] Weigel, D. (2002) Arabidopsis: A laboratory manual. Cold Spring Harbor Laboratory Press, New York, 102145.

[53] Bradford, M.M. (1976) Rapid and sensitive method for the quantitation of microgram quantities of protein utilizing the principle of protein-dye binding. Analytical Biochemistry, 72, 248-254. doi:10.1016/0003-2697(76)90527-3
[54] Laemmli, U.K. (1970) Cleavage of structural proteins during the assembly of the head of bacteriophage T4. Nature, 227, 680-685. doi:10.1038/227680a0

[55] Azevedo, C., Santos-Rosa, M.J. and Shirasu, K. (2001) The U-box protein family in plants. Trends in Plant Science, 6, 354-358. doi:10.1016/S1360-1385(01)01960-4

[56] Andersen, P., Kragelund, B.B., Olsen, A.N., Larsen, F.H., Chua, N., Poulsen, F.M. and Skriver, K. (2004) Structure and biochemical function of aprototypical Arabidopsis U-box domain. Journal of Biological Chemistry, 279, 40053-40061. doi:10.1074/jbc.M405057200

[57] Wiborg, J., O'Shea, C. and Skriver, K. (2008) Biochemical function of typical and variant Arabidopsis thaliana U-box E3 ubiquitin-protein ligases. Biochemical Journal, 413, 447-457. doi:10.1042/BJ20071568

[58] Thomas, S.G. and Franklin-Tong, V.E. (2004) Self-incompatibility triggers programmed cell death in Papaver pollen. Nature, 429, 305-309. doi:10.1038/nature02540

[59] Yang, C.W., González-Lamothe, R., Ewan, R.A., Rowland, O., Yoshioka, H., Shenton, M., Ye, H., O’Donnell, E., Jones, J.D.G. and Sadanandom, A. (2006) The E3 ubiquitin ligase activity of Arabidopsis PLANTU-BOX17 and its functional tobacco homolog ACRE276 are required for cell death and defense. The Plant Cell, 18, 1084-1098. doi:10.1105/tpc. 105.039198

[60] Itoh, H., Ueguchi-Tanaka, M., Sato, Y., Ashikari, M. and Matsuoka, M. (2002) The gibberellin signaling pathway is regulated by the appearance and disappearance of SLENDER RICE1 in nuclei. The Plant Cell, 14, 57-70. doi: $10.1105 /$ tpc. 010319

[61] Spartz, A.K., Lee, S.H., Wenger, J.P., Gonzalez, N., Itoh, H., Inzé, D., Peer, W.A., Murphy, A.S., Overvoorde, P.J. and Gray, W.M. (2012) The SAUR19 subfamily of SMALL AUXIN UP RNA genes promote cell expansion. The Plant Journal, 70, 978-990. doi:10.1111/j.1365-313X.2012.04946.x

[62] Komeda, Y. (2004) Genetic regulation of time to flowering Arabidopsis thaliana. Annual Review of Plant Biology, 55, 521-535. doi:10.1146/annurev.arplant.55.031903.141644

[63] Yu, H., Ito, T., Wellmer, F. and Meyerowitz, E.M. (2004) Floral homeotic genes are targets of gibberellins signaling in flower. Proceedings of the National Academy of Sciences USA, 101, 7827-7832.

[64] Weiss, D. and Ori, N. (2007) Mechanisms of cross talk between gibberellin and other hormones. Plant Physiology, 144, 1240-1246. doi:10.1104/pp.107.100370

[65] Acosta, M.G., Ahumada, M.A., Lassaga, S.L. and Casco, V.H. (2010b) Abiotic stress effect on gene expression of ARM repeats proteins in A. thaliana. Book of AbstractsXXIII Meeting Argentina Plant Physiology, 1, 205.

[66] Cabrillac, D., Cock, J.M., Dumas, C. and Gaude, T. (2001) The $\mathrm{S}$ locus receptor kinase is inhibited by thioredoxins and activated by pollen coat proteins. Nature, 410, 220223. doi: $10.1038 / 35065626$

[67] Griffiths, J., Murase, K., Rieu, I., Zentella, R., Zhang, Z.L., Powers, S.J., Gong, F., Phillips, A.L., Hedden, P. and Sun, T.P. (2007) Genetic characterization and func- 
tional analysis of the GID1 gibberellin receptors in Arabidopsis. The Plant Cell, 18, 3399-3414.

doi:10.1105/tpc.106.047415

[68] Blazquez, M.A., Green, R., Nilsson, O., Sussman, M.R. and Weigel, D. (1998) Gibberellins promote flowering of Arabidopsis by activating the LEAFY promoter. The Plant Cell, 10, 791-800.

[69] Sun, T.P. and Gubler, F. (2004) Molecular mechanism of gibberellin signaling in plants. Annual Review of Plant Biology, 55, 197-223.

doi:10.1146/annurev.arplant.55.031903.141753

[70] Ueguchi-Tanaka, M., Ashikari, M., Nakajima, M., Itoh, H., Katoh, E., Kobayashi, M., Chow, T.Y., Hsing, Y.I., Kitano, H. and Yamaguchi, I. (2005) GIBBERELLIN INSENSITIVE DWARF1 encodes a soluble receptor for gibberellin. Nature, 437, 693-698. doi:10.1038/nature 04028

[71] Hartweck, L.M. and Olszewski, N.E. (2006) GIBBERELLIN INSENSITIVE DWARF1 is a gibberellin receptor that illuminates and raises questions about GA signaling. The Plant Cell, 18, 278-282. doi:10.1105/tpc.105.039958

[72] Yee, D. and Goring, D.R. (2009) The diversity of PUB E3 ubiquitin ligases: From upstream activators to downstream target substrates. Journal of Experimental Botany, 60, 1109-1121. doi:10.1093/jxb/ern369

[73] Cho, S.K., Chung, H.S., Ryu, M.Y., Park, M.J., Lee,
M.M., Bahk, Y.Y., Kim, J., Pai, H.S. and Kim, W.T. (2006) Heterologous expression and molecular and cellular characterization of CaPUB1 encoding a hot pepper UBoxE3 ubiquitin ligase homolog. Plant Physiology, 142, 1664-1682. doi:10.1104/pp.106.087965

[74] Cho, S.K., Ryu, M.Y., Song, C., Kwak, J.M. and Kim, W.T. (2008) Arabidopsis PUB22 and PUB23 are homologous U-box E3 ubiquitin ligases that play combinatory roles in response to drought stress. The Plant Cell, 20, 1899-1914. doi:10.1105/tpc.108.060699

[75] Shen, G., Yan, J., Pasapula, V., Luo, J., He, C., Clarke, A.K. and Zhang, H. (2007) The chloroplast protease subunit ClpP4 is a substrate of the E3 ligase AtCHIP and plays an important role in chloroplast function. The Plant Journal, 49, 228-237. doi:10.1111/j.1365-313X.2006.02963.x

[76] Alonso-Ramírez, A., Rodríguez, D., Reyes, D., Jiménez, J.A., Nicolás, G., López-Climent, M., Gómez-Cadenas, A. and Nicolás, C. (2009) Cross-talk between gibberellins and salicylic acid in early stress responses in Arabidopsis thaliana seeds. Plant Signal Behavior, 4, 750-751. doi:10.4161/psb.4.8.9175

[77] Letunic, I. and Bork, P. (2007) Interactive tree of life (iTOL): An on line tool for phylogenetic tree display and annotation. Bioinformatics, 23, 127-128. doi:10.1093/bioinformatics/bt1529

\section{ABBREVIATIONS}

ARM: armadillo

PUB: plant U-box

ARC1: armadillo-repeats containing protein-1

SRK: S-locus receptor kinase

SLG: S-locus glycoprotein 